\title{
Tinjauan Literatur Sistematik Tentang Penerapan Motion Capture Pada Proses Produksi Animasi
}

\author{
Qolbun Salim As Shidiqi ${ }^{1}$, Ema Utami ${ }^{2}$, Amir Fatah Sofyan ${ }^{3)}$ \\ ${ }^{1,2,3}$ Magister Teknik Informatika Universitas AMIKOM Yogyakarta \\ 1,2,3 Yogyakarta \\ 1'qolbun.s@students.amikom.ac.id, ${ }^{2}$ emma@nrar.net, ${ }^{3}$ amir@amikom.ac.id
}

\begin{abstract}
Abstrak
Motion capture adalah metode atraktif untuk membuat gerakan dalam animasi komputer. Mocap dapat menyajikan gerakan yang realistis dan memberikan nuansa dan detil khususnya pada pameran tertentu. Mocap memungkinkan bagi aktor dan sutradara untuk bekerja bersama membuat gerakan tertentu yang diinginkan, yang itu akan sulit dilakukan pada animator yang bekerja secara manual. Teknologi motion capture dibutuhkan dalam berbagai aplikasi, khususnya animasi yang terus berkembang pesat. Teknik yang digunakan dapat menggunakan penanda maupun tanpa penanda (markerless).

Ada banyak algoritma untuk motion capture salah satunya metode Active Appearance Model (AAM). Metode ini mampu melakukan capture titik-titik landmark pada wajah dengan baik. Penelitian ini diarahkan untuk mengembangkan teknik markerless motion capture dengan menggunakan AAM pada wajah. Dari metode yang ada perlu diketahui mana metode yang paling efektif untuk digunakan, untuk itu penelitian ini membandingkan dua metode AAM, yaitu IAIA (Inverse Additive Image Alignment) dan ICIA (Inverse Compositional Image Alignment) yang dilakukan secara real time. AAM merupakan metode yang sering digunakan pada pemodelan wajah (face modeling). Namun, AAM dapat juga bermanfaat untuk implementasi lainnya. Dalam aplikasi tertentu, langkah pertama adalah mencocokan AAM dengan gambar, yakni parameter model ditemukan terlebih dahulu untuk memaksi-malkan kecocokan antara contoh model dengan gambar input.
\end{abstract}

Kata kunci:Animasi, motion capture, AAM, IAIA, ICIA

\section{PENDAhULUAN}

Bersamaan dengan kemajuan teknologi, animasi berkembang dengan cukup pesat sehingga menarik minat masyarakat dari berbagai kalangan. Terbukti dengan maraknya animasi animasi yang ditayangkan oleh stasiun televisi maupun bioskop.

Perkembangan animasi seiring dengan perkembangan dunia pertelevisian. Pada awalnya diciptakanlah animasi berbasis dua dimensi (2D Animation). Yakni objek yang dianimasi mempunyai ukuran panjang (x-axis) dan lebar (y-axis) saja. Realisasi nyata dari perkembangan animasi dua dimensi yang cukup revolusioner berupa dibuatnya filmfilm kartun. Seven Dwarfs (1937) dan Fantasia (1940) dari Walt Disney adalah karya-karya film kartun yang melegenda sampai sekarang. Bahkan beberapa tokohtokoh kartun buatan Walt Disney yang lain masih dapat bertahan dan populer sampai saat ini mekipun pembuatan film-film tersebut dikerjakan hampir 500 tahun yang lalu. Perkembangan dunia animasi computer sekarang sudah sangat pesat, apalagi sejak diciptakannya animasi berbasis tiga dimensi ( 3D Animation) yang mempunyai ukuran panjang, lebar, dan tinggi ( $\mathrm{Z}$-axis) maka objek dan pergerakkannya hampir mendekati kenyataan aslinya.

Motion capture (mocap) adalah metode atraktif untuk membuat gerakan dalam animasi komputer. Mocap dapat menyajikan gerakan yang realistis dan memberikan nuansa dan detil khususnya pada pameran tertentu. Mocap memungkinkan bagi aktor dan sutradara untuk bekerja bersama membuat gerakan tertentu yang diinginkan, yang itu akan sulit dilakukan pada animator yang bekerja secara manual. Sedangkan menurut Sharma (2013), motion capture mengandalkan perekaman dan pengambilan sempel gerakan manusia, hewan dan benda mati sebagai data 3 dimensi. 
Teknologi motion capture dibutuhkan dalam berbagai aplikasi, khususnya animasi yang terus berkembang pesat. Teknik yang digunakan dapat menggunakan penanda maupun tanpa penanda (markerless). Metode Active Appearance Model (AAM) mampu melakukan capture titik-titik landmark pada wajah dengan baik. Penelitian ini diarahkan untuk mengembangkan teknik markerless motion capture dengan menggunakan AAM pada wajah.

Dari metode yang ada perlu diketahui mana metode yang paling efektif untuk digunakan, untuk itu penelitian ini membandingkan dua metode AAM, yaitu IAIA (Inverse Additive Image Alignment) dan ICIA (Inverse Compositional Image Alignment) yang dilakukan secara real time.

Paper ini ditulis untuk memberikan gambaran kepada peneliti tentang penggunaan Metode AAM secara realtime sebagai mentode dalam proses pembuatan motion capture. Diharapkan setelah mendapatkan gambaran tentang penggunaan metode AAM dapat digunakan dalam pembuatan Motion Capture dengan efektif sehingga dapat mempercepat proses produksi animasi.

\section{METODE PENELITIAN}

Dalam proses motion capture tahapan pertama yang dilakukan adalah tahapan pengumpulan dataset, berbagai penelitian mengambil dataset dari berbagai sumber FRANCK, IMM, JIAPEI, C3D, LFPW, The Bassai Dai dan lain lain. Beberapa penelitian membuat objek dataset sendiri sesuai dengan objek yang akan diteliti. Metode penelitian eksperimental menjadi metode yang dipakai pada tinjauan literature yang ada, sehingga peneliti akan menggunakan metode yang sama dalam pembuatan gerak animasi dengan mengambil dataset untuk di adopsi point landmarknya.Tahapan metode penelitian diurutkan secara sistematis dengan mengacu pada tinjauan literature yang ada agar pelaksanaan penelitian dapat berjalan dengan baik dijelaskan dalam gambar dibawah ini.

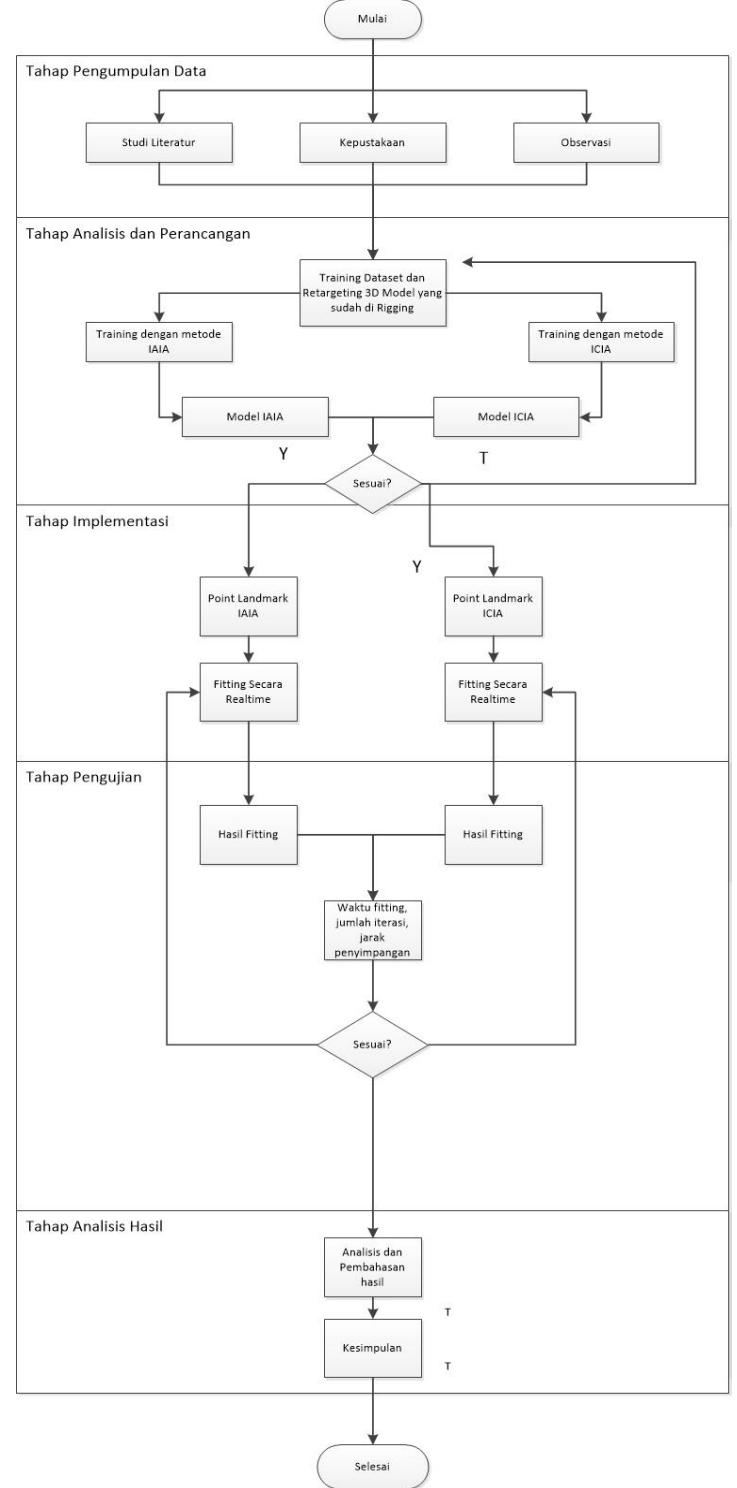

Gambar 1. Metode Penelitian

\section{TINJAUAN PUSTAKA}

Motion capture adalah metode atraktif dalam membuat gerakan animasi komputer. Hal ini memungkinkan bagi aktor dan sutradara untuk bekerja bersama membuat untuk gerakan tertentu yang diharapkan, yang mana hal tersebut akan sulit dilakukan oleh animator yang bekerja secara manual. Mocap dapat menyajikan gerakan yang realistis dan memberikan nuansa dan detil khususnya pada pameran tertentu. Mocap memungkinkan bagi aktor dan sutradara untuk bekerja bersama membuat gerakan tertentu yang diinginkan, yang itu akan sulit dilakukan pada animator yang bekerja secara manual (Sukoco, 14, 2011).

Istilah motion capture menunjuk pada beberapa teknik untuk merekam pergerakan manusia, hewan atau subyek lain, dengan 
menggunakan data rekaman pada penganimasian karakter tiruan. Teknik motion capture telah berkembang secara luas pada penggunaan film, televisi dan industri video game; dan berkembang dari bidang studi biomekanik sampai seni pertunjukan. Computer vision dapat membuat data animasi menjadi lebih mudah dibuat. Teknik yang sekarang dikembangkan jauh lebih cepat pengerjaannya dalam membuat animasi.

Active Appearance Model merupakan metode yang sering digunakan pada pemodelan wajah (face modeling). Namun, AAM dapat juga bermanfaat untuk fimplementasi lainnya. Dalam aplikasi tertentu, langkah pertama adalah mencocokan AAM dengan gambar, yakni parameter model ditemukan terlebih dahulu untuk memaksimalkan kecocokan antara contoh model (model instance) dengan gambar input. Parameter model kemudian dapat digunakan dalam berbagai aplikasi. Sebagai contoh, parameter ini dapat digunakan sebagai classifier untuk menghasilkan algoritma pengenalan wajah. Pada model yang sama dapat digunakan untuk pengenalan wajah, estimasi pose, dan pengenalan ekspresi. Pencocokan AAM pada gambar merupakan permasalahan non-linear. Pendekatan yang umum dengan cara berulang-ulang memecahkan incremental additive update pada parameter (koefisien shape dan appearance). Dengan nilai parameter shape saat ini, dimungkinkan untuk mengubah gambar input ke dalam frame model koordinat kemudian menghitung error image antara contoh model saat ini dengan gambar AAM yang cocok. Pada kebanyakan algoritma sebelumnya, dapat diasumsikan bahwa terdapat linear konstan antara error image dengan additive incremental update pada parameter. Asumsi tersebut pada umumnya kurang tepat, karena akan menghasilkan fitting AAM yang kurang bagus performanya, baik dalam jumlah iterasi untuk konvergen maupun akurasi hasil akhir.

Algoritma inverse compositional ditemukan untuk mengatasi hal tersebut. Untuk menggunakan algoritma inverse compositional, pertama kita harus mendapat first order approximation pada kumpulan operator dari composition dan inversion. Algoritma inverse compositional juga memungkinkan tindakan yang berbeda pada variasi appear-ance. Kita dapat melakukan variasi appearance pada langkah precomputation dan mengeliminasi besarnya perhitung-an dalam komputasi. Pada dasarnya hanya ada dua jenis linear model shape dan appearance yaitu model yang shape dan appear- ance-nya independen serta model yang memparameter- kan shape dan appearance dengan satu himpunan para- meter linear. Kita menyebut himpunan yang pertama se- bagai independent shape and appearance models (independent AAMs) dan yang kedua adalah combined shape and appearance (combined AAMs).

\section{HASIL DAN PEMBAHASAN}

Dilakukan tinjauan literature secara sistematik pada beberapa penelitian sejenis diantaranya yaitu penelitian dari I Dewa Bagas Suryajaya yang melakukan penelitian penerapan Teknik motion capture dalam proses pembuatan animasi 3D menggunakan Microsoft Kinect (Suryajaya, 2015). Kemudian penelitian Muhammad Nasrulloh yang melakukan penelitian ekspresi wajah non-human model $3 \mathrm{D}$ berbasis radial basis function menggunakan data facial motion capture (Nasrulloh, 2015). Kemudian penelitian M Iqtait yang melakukan penelitian pengenalan wajah dengan menggunakan Active Shape Model (ASM) dan Active Appearance Model (AAM) (Iqtait, 2018). Kemudian penelitian Troy yang melakukan transformasi ruang $2 \mathrm{D}$ ke $3 \mathrm{D}$ pada wajah berbasis data marker menggunakan radian basis function (RBF) (Troy, 2016). Kemudian penelitian Didit Prasetyo yang melakukan permodelan karakter animasi wayang orang berbasis motion capture (Prasetyo, 2017). Kemudian penelitian Dana K. Urribarri yang melalukan visualisasi untuk membandingkan karate kata dengan motion capture (Urribarri, 2019)

Rincian perbandingan analisis dari beberapa penelitian yang digunakan sebagai ulasan dalam penggunaan penerapan motion capture dapat dilihat dalam Tabel 1 berikut ini.

Tabel 1. Analisis Perbandingan Proses Tinjauan

\begin{tabular}{|l|c|}
\hline $\begin{array}{l}\text { N } \\
o\end{array}$ & Judul \\
\hline 1 & Teknik Motion Capture Dalam Proses \\
\hline
\end{tabular}




\begin{tabular}{|c|c|}
\hline \multirow{15}{*}{$\begin{array}{l}\mathrm{N} \\
\mathrm{o}\end{array}$} & $\begin{array}{l}\text { Pembuatan Animasi 3D Menggunakan } \\
\text { Microsoft Kinect }\end{array}$ \\
\hline & Tujuan Penelitian \\
\hline & $\begin{array}{l}\text { Penelitian tersebut bertujuan untuk: } \\
\text { Mengetahui bentuk area aman dalam } \\
\text { penggunaan Kinect dan pengaruh } \\
\text { penggunaan penanda serta kecepatan ideal } \\
\text { untuk melakukan teknik motion capture } \\
\text { menggunakan kinect }\end{array}$ \\
\hline & Kesimpulan \\
\hline & $\begin{array}{l}\text { Kinect dapat digunakan sebagai alat } \\
\text { motion capture dengan syarat } \\
\text { menggunakan driver OpenNI dan software } \\
\text { Brekel Kinect sebagai software untuk } \\
\text { mengubah hasil tangkapan gerak menjadi } \\
\text { file yang dapat digunakan dalam } \\
\text { penganimasian 3D. }\end{array}$ \\
\hline & $\begin{array}{l}\text { Software yang digunakan: OpenNI dan } \\
\text { software Brekel Kinect dan 3Dsmax }\end{array}$ \\
\hline & $\begin{array}{l}\text { Dataset : Membuat dataset sendiri berupa } \\
\text { motion dari figur }\end{array}$ \\
\hline & Saran atau Kelemahan \\
\hline & $\begin{array}{l}\text { Menggunakan perangkat khusus yaitu } \\
\text { kamera Kinect sehingga sulit } \\
\text { diimplementasikan oleh orang yang tidak } \\
\text { memiliki perangkat tersebut }\end{array}$ \\
\hline & Judul \\
\hline & $\begin{array}{l}\text { Ekspresi Wajah Non-Human Model 3D } \\
\text { Berbasis Radial Basis Function } \\
\text { Menggunakan Data Facial Motion Capture }\end{array}$ \\
\hline & Tujuan Penelitian \\
\hline & $\begin{array}{l}\text { Tujuan dari penelitian ini adalah untuk } \\
\text { melakukan studi teknik Motion } \\
\text { Capture sebagai teknik penangkapan gerak } \\
\text { model yang akan dikonversikan pada } \\
\text { karakter animasi "MIPO". Dan } \\
\text { penggunaan metode Radial Basis Function } \\
\text { untuk } \\
\text { face exaggeration agar dapat menghasilkan } \\
\text { ekspresi yang dapat mengikuti } \\
\text { pergerakan model peraga pada karakter } \\
\text { animasi "MIPO" dengan menggunakan } \\
\text { Motion Capture Data dari wajah manusia. }\end{array}$ \\
\hline & Kesimpulan \\
\hline & $\begin{array}{l}\text { Proses persiapan karakter yang akan } \\
\text { digunakan dalam penelitian ini adalah } \\
\text { karakter original. Proses rigging adalah } \\
\text { menggunakan teknik Weightpaint yang } \\
\text { memudahkan proses persiapan karakter. } \\
\text { Rigging dengan teknik Weightpaint sangat }\end{array}$ \\
\hline
\end{tabular}

\begin{tabular}{|c|c|}
\hline \multirow{10}{*}{$\mathrm{N}$} & $\begin{array}{l}\text { sederhana karena hanya memerlukan } \\
\text { waktu yang singkat dalam memasangkan } \\
\text { Bone pada karakter karena didukung } \\
\text { dengan system armature deform yang } \\
\text { secara otomatis bone terhubung pada Mesh } \\
\text { model. }\end{array}$ \\
\hline & $\begin{array}{l}\text { Software yang digunakan: Blender } \\
\text { Dataset : Membuat dataset sendiri berupa } \\
\text { motion dari peraga untuk fitting, dan } \\
\text { menggunakan data C3D pada proses } \\
\text { training }\end{array}$ \\
\hline & Kelemahan dan Saran \\
\hline & $\begin{array}{l}\text { Beberapa penentuan fitur yang } \\
\text { memungkinkan untuk dapat } \\
\text { dikembangkan adalah sebagai berikut: } \\
\text { 1. Memasang data titik fitur ke obyek } \\
\text { karakter 3D perlu dilakukan untuk } \\
\text { memastikan keakuratan ekspresi lebih } \\
\text { jauh. } \\
\text { 2. Perlunya dilakukan percobaan untuk } \\
\text { model karakter wajah yang lebih } \\
\text { ekstrim seperti mata berbentuk segi } \\
\text { empat, bibir yang berbentuk tidak } \\
\text { wajar, atau pada model benda mati } \\
\text { untuk menguji kemampuan dari } \\
\text { metode yang digunakan. } \\
\text { Penerapan metode yang sama dengan } \\
\text { model yang berbeda bentuk dan ukuran } \\
\text { dengan ekspresi yang dibuat berlebihan. } \\
\text { Dan dapat berekspresi melebihi manusia } \\
\text { normal }\end{array}$ \\
\hline & Judul \\
\hline & $\begin{array}{l}\text { Feature extraction for face recognition via } \\
\text { Active Shape Model (ASM) and Active } \\
\text { Appearance Model (AAM) }\end{array}$ \\
\hline & Tujuan Penelitian \\
\hline & $\begin{array}{l}\text { Tujuan dari penelitian ini adalah untuk } \\
\text { membandingkan performa algoritma ASM } \\
\text { dan AAM dengan parameter kecepatan } \\
\text { dan juga kecocokan dalam pengenalan } \\
\text { wajah. }\end{array}$ \\
\hline & Kesimpulan \\
\hline & $\begin{array}{l}\text { Dalam tulisan ini, ekstraksi fitur wajah } \\
\text { menggunakan AAM, ASM Algoritma } \\
\text { dengan database wajah LFPW. Dihasil } \\
\text { percobaan, kami menemukan bahwa } \\
\text { model ASM lebih cepat dan mencapai titik } \\
\text { sifat yang lebih tepat lokasi daripada } \\
\text { model AAM, dan model AAM } \\
\text { memberikan kecocokan yang lebih baik } \\
\text { dengan tekstur gambar. }\end{array}$ \\
\hline
\end{tabular}




\begin{tabular}{|c|c|}
\hline & $\begin{array}{l}\text { Software yang digunakan: Matlab R2016a } \\
\text { Dataset : LFPW database }\end{array}$ \\
\hline & Saran dan Kelemahan \\
\hline & $\begin{array}{l}\text { Di penelitian selanjutnya hasil ini dapat } \\
\text { dibandingkan dengan Model lain yang } \\
\text { berkaitan dengan pengenalan wajah dan } \\
\text { para peneliti dapat meningkatkan dan } \\
\text { membangun model gabungan } \\
\text { menggunakan ASM dan AAM model yang } \\
\text { bersama-sama mengoptimalkan lokasi titik } \\
\text { ciri yang tepat dan memberikan kecocokan } \\
\text { yang lebih baik dengan gambar tekstur. }\end{array}$ \\
\hline $\begin{array}{l}\mathrm{N} \\
\mathrm{o}\end{array}$ & Judul \\
\hline 4 & $\begin{array}{l}\text { Transformasi Ruang 2D Ke 3D Pada } \\
\text { Animasi Wajah Berbasis Data Marker } \\
\text { Menggunakan Radial Basis Function }\end{array}$ \\
\hline & Tujuan Penelitian \\
\hline & $\begin{array}{l}\text { Tujuan dari penelitian ini adalah untuk } \\
\text { menguji penerapan Radial Basis Function } \\
\text { yang digunakan untuk menentukan posisi } \\
\text { titik fitur pada wajah model 3D. }\end{array}$ \\
\hline & Kesimpulan \\
\hline & $\begin{array}{l}\text { Transformasi ruang RBF dapat memetakan } \\
\text { ulang titik fitur wajah model 3D bahkan } \\
\text { jika wajah sumber animasi hanya } \\
\text { ditangkap oleh satu kamera dan hanya } \\
\text { memberikan informasi titik marker secara } \\
\text { 2D. } \\
\text { Dataset: Membuat dataset sendiri berupa } \\
\text { capture ekspresi dari peraga }\end{array}$ \\
\hline & Saran dan Kelemahan \\
\hline & $\begin{array}{l}\text { Otomatisasi pemetaan ulang titik fitur } \\
\text { wajah karakter animasi dapat dilakukan } \\
\text { bukan hanya dengan RBF Multiquadric. } \\
\text { Perlu dilakukan penelitian pada metode } \\
\text { interpolasi yang lain sehingga didapatkan } \\
\text { pemetaan yang lebih sesuai dan mendekati } \\
\text { ekspresi wajah sumber animasi. Penelitian } \\
\text { ini tidak bisa berhenti hanya pada } \\
\text { pemetaan ulang titik fitur pada wajah } \\
\text { karakter animasi, namun dilanjutkan pada } \\
\text { membangun permukaan wajah karakter } \\
\text { animasi. Sehingga ekspresi yang } \\
\text { diinginkan dapat terlihat dan diterapkan } \\
\text { pada dunia animasi. }\end{array}$ \\
\hline $\begin{array}{l}\mathrm{N} \\
\mathrm{o}\end{array}$ & Judul \\
\hline 5 & $\begin{array}{l}\text { Pemodelan Karakter Animasi Wayang } \\
\text { Orang Berbasis Motion Capture }\end{array}$ \\
\hline
\end{tabular}

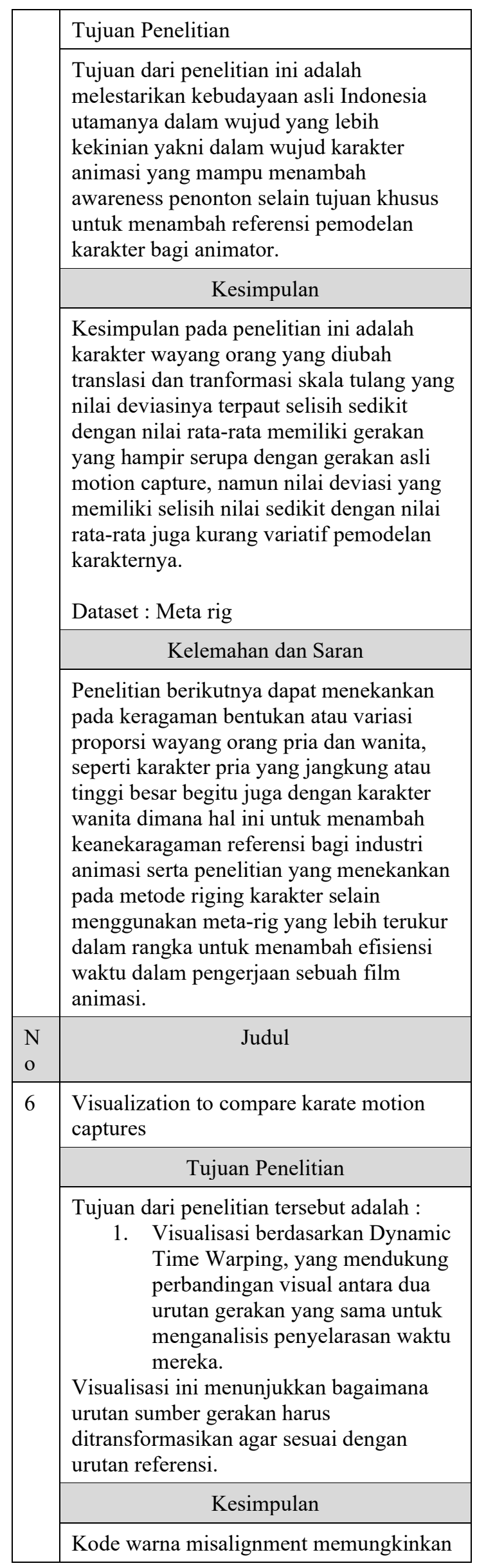


pengguna dapat dengan mudah

menemukan kerangka waktu di mana urutannya berbeda. Alat kami bisa mudah diperpanjang dengan menunjukkan bingkai video yang sesuai atau kerangka yang terkait berpose atas permintaan pengguna.

Dataset : The Bassai Dai

Kelemahan dan Saran

Untuk penelitian selanjutnya, dapat dilakukan dengan meningkatkan interaksi yang sesuai untuk eksplorasi (misalnya, pembesaran semantik) dan menambahkan kemungkinan untuk membandingkan lebih dari dua urutan sekaligus. Selain itu, kami akan mengeksplorasi lebih lanjut kemungkinan dengan penggunaan DTW dan membandingkan pertimbangan MoCaps kecepatan aktual mereka

\section{KESIMPULAN DAN SARAN \\ a. Kesimpulan}

Paper ini menganalisis penggunaan Motion Capture dengan berbagai metode dan media dimensi dari animasi yang diproduksi untuk membantu pemecahan masalah dan meningkatkan produktivitas, keefisiensian, keefektifan dalam porses produksi animasi. Dapat diambil kesimpulan bahwa algoritma AAM dapat digunakan secara efektif dalam proses pembuatan gerak animasi, sehingga dapat membantu proses produksi animasi dan diharapkan dapat meningkatkan produktivitas.

\section{b. Saran}

Diharapkan peneliti selanjutnya dapat melakukan tinjauan literature lebih dalam dengan berfokus pada salah satu algoritma. Sehingga rekomendasi yang didapatkan menjadi lebih mengerucut.

\section{REFERENSI}

Thomas, Frank dan Ollie Johnston.(1981). The Illusion of Life: Disney Animation, Walt Disney Production, New York

Robert, Steve.(2013). Character Animation: 2D Skills for Better 3D, Taylor \& Francis, London

Santoso, Bambi Gunawan.(2013). Nganimasi Bersama Mas Be!, PT Elex Media Komputindo, Jakarta

Matthews, Ian., Baker, Simon.(2004). Active Appearance Models Revisited, Second Edition, Addison Wiley, Canada
Michael Gleicher and Nicola Ferrier.(2002). Evaluating Video-Based Motion Capture, Proceedings of Computer Animation.

Adam G. Kirk, James F. O'Brien, David A. Forsyth.(2005). Skeletal Parameter Estimation from Optical Motion Capture Data, Proceedings of IEEE Conf. on Computer Vision and Pattern Recognition (CVPR).

Sukoco.(2011). Teknologi Motion Capture Untuk Pembuatan Film Animasi 3D, http://ejournal.unsa.ac.id/index.php/ijcs s/issue/view/8. Diakses pada tanggal 17 Juni 2020

I Dewa Bagus Suryajaya.(2015). Teknik Motion Capture Dalam Proses Pembuatan Animasi 3D Menggunakan Microsoft Kinect, Seminar Nasional Teknologi Informasi dan Multimedia, Yogyakarta

Troy, Pranowo.(2016). Transformasi Ruang 2D Ke 3D Pada Animasi Wajah Berbasis Data Marker Menggunakan Radial Basis Function, Journal of Animation and Games Studies, Vol. 2 No.2

Didit Prasetyo, Rabendra Yudistira Alamin, (2017). Pemodelan Karakter Animasi Wayang Orang Berbasis Motion Capture, Idea Jurnal Desain, Vol. 16, No. 2

Dana K. Urribarri, Mart'1n L. Larrea1, Silvia M. Castro, Enrico Puppo, (2019). Visualization to compare karate motion captures XXV Congreso Argentino de Ciencias de la Computación

Timothy F. Cootes, Gareth J. Edwards, and Christopher J. Taylor.(2001). Active Appearance Models, IEEE Transactions, On Pattern Analysis And Machine Intelegence, Vol. 23, No. 6

M Iqtait, F S Mohamad, M Mamat.(2017). Feature extraction for face recognition via Active Shape Model (ASM) and Active Appearance Model (AAM), IOP Conf. Series: Materials Science and Engineering 332

Lanitis, Andreas., Taylor, Chris J., Cootes, Timothy F.(1997). Automatic Interpretation and Coding of Face Image Using Flexible Models, Vol 19(7): 743-756, IEEE Transactions on Pattern Analysis and Machine Intelligence. 
Tri Afirianto, Mochamad Hariadi.(2013). Facial Motion Capture Menggunakan Active Appearance Model Berbasis Blender, Seminar Nasional Teknologi Informasi dan Multimedia 2013

Muhammad Nasrulloh.(2015). Ekspresi Wajah Non-Human Model 3D Berbasis Radial Basis Function Menggunakan Data Facial Motion Capture, Tesis, Fakultas Teknologi Industri, Institut Teknologi Sepuluh Nopember, Surabaya 